\title{
Entrepreneurship is the Driving Force of the Pension Industry Development
}

\author{
Wenying Bao ${ }^{1} \&$ Jianyong $\mathrm{Shi}^{1}$ \\ ${ }^{1}$ School of Management, Shanghai University of Engineering Science, Shanghai, China \\ Correspondence: Wenying-Bao, Room602, 9th Building, NO.158, Yulan Road, Pudong District, Shanghai, China.
}

Tel: 86-136-2187-6737. E-mail: 602427909@qq.com

Received: August 20, 2014 Accepted: October 22, $2014 \quad$ Online Published: January 10, 2015p

doi:10.5430/sass.v2n1p12 URL: http://dx.doi.org/10.5430/sass.v2n1p12

\begin{abstract}
In accordance with the standards of the world health organization, we have begun to enter elderly society, and the proportion of aging population will be rising in the future. Due to great changes have been taken place in population structure in recent years, the demand of endowment enterprises is increasing. To solve endowment problem, we can not simply rely on the government, we also need to inject some fresh blood to maintain its vitality. Now it is time for entrepreneurs who were the first rich people since the founding of new China to undertake the responsibility of the society. If they continue to play their best areas: innovation, planning, management, organization, coordination, and put the entrepreneurial spirit into endowment career, and what a piece of heaven and earth will be clearing out? In this article, we mainly analyse the subtle connection between the entrepreneurial spirit and endowment career, and try to find the balance point in them.In this way, we can promote the development of endowment career. Even we can reach the harmony between the entrepreneurial spirit and endowment career that is to say the Unity of spirit and matter.
\end{abstract}

Keywords: The entrepreneurial spirit, endowment career, aging, entrepreneur, innovation

\section{The Main Problems in the Current Endowment Undertakings of China}

\subsection{Risks from the Gap between Pension Income and Expense}

Endowment insurance system was implemented very late in China. In 1991, the State Council of China decided to change the endowment insurance system for enterprise employees, and therefore personal account was introduced by drawing lessons from Chile's model. After five years of exploration and pilot, a partial funding system which combines social pooling accounts with personal accounts was gradually established as the endowment insurance system all over the country until 1996. Hereby, the prelude of the retirement pensions under empty account operation is exposed. There may be great risks from the gap between the basic pension incomes and expenses in the future. In addition, personal accounts are emptily operated in the endowment insurance system for the urban enterprise employees. The empty operation of pension accounts is generally caused by the factors of the following two aspects: (1) the historical pension debts for the employees to work before China's reform; (2) the pensions collected from social pooling accounts are insufficient. According to a research report from Chinese Academy of Social Sciences Study, the personnel account debt was up to RMB740 billion in 2004; Chinese personal accounts bookkeeping amount was RMB1.9 trillion, among which the amount of the real accounts were RMB203.9 billion, equal to the gap of RMB1.7 trillion.

\subsection{The Unreality of Home Care Service Model}

Since the one-child policy was comprehensively implemented in China in the 1970s. A large number of "421" family or "422" family have emerged - that is, the life of four elderly parents and one or two children is necessarily afforded by a young couple in a family. Thus, undoubtedly, makes the younger generation already overwhelmed by a working pressure out of breath, not to mention the quality of life. Worse, great numbers of the elderly are unable to enjoy the peaceful twilight years after retirement, but are likely to continue the "work" of babysitting the grandchildren. 


\subsection{The Short Supply of the Nursing Institutions for the Elderly}

Wholly-owned welfare homes or nursing homes are only applicable to a small number of objects, while the apartments for the elderly or socially-organized nursing homes are expensive and non-standardized, so that there are no appropriate nursing institutions for many elderly people to go. Moreover, the life of the "empty-nest" elderly whose children work and live far away from them and the elderly losing their only child is heart-struck. This year, a hot weather of $40^{\circ} \mathrm{C}$ has been continued for many days, but air conditioning is not installed in the elderly who live alone under a poor living condition, and some of them pass away because of suffering heat stroke, making the public extremely distressed. Now, the community centers at some streets have been opened to the elderly for enjoying the cool, but this is only a measure to solve the superficial problems. Therefore, does a harmonious society exist in China if the life quality of the elderly is maintained in such a low standard?

\section{The Meaning of Entrepreneurship}

\subsection{The Definition of Entrepreneurs}

Entrepreneurs refer to the individuals full of the spirit in adventure, who can promote the development of economy by discovering and employing more efficient production methods. The works of Say Jean Baptiste shows clearly that a value can be created by entrepreneurs who transfer economic resources from the fields of a low efficiency to those of a high efficiency. Entrepreneurs are those individuals devoting themselves to creative destructions, who make the obsolete methods and products eliminated by the new methods and products through continuous innovations, so as to promote economic development. The view of both Say Jean Baptiste and Joseph Alois Schumpeter on deeming entrepreneurs as catalysts and innovators to promote the development of economy turns into a foundation for the current researches of entrepreneurship theory.

\subsection{The Meaning of Entrepreneurship}

To define entrepreneurship is indispensable with an analysis of entrepreneurship's meaning. At present, entrepreneurship is domestically translated into "starting a new business", "the science of new venture creation", "enterprising spirit", "entrepreneurial spirit", etc. Accordingly, it is translated by the author into "the science of new venture creation" in terms of the academic research field, but "entrepreneurial spirit" in terms of a social phenomenon. In this paper, the relationship between entrepreneurial spirit and endowment undertakings is mainly studied, and therefore entrepreneurial spirit is better applicable to the meaning of entrepreneurship.

Entrepreneurial spirit is a summary to all excellent qualities of entrepreneurs in the establishment and management of enterprises. Entrepreneurs have been promoted to develop a unique spirit known as "entrepreneurial spirit", because of the role and responsibilities of entrepreneurs in the history of human development, the position and practices in the development of society, and especially the fierce competition in the modern market economy. Competition, innovation, adventure, responsibility, integrity, cooperation, pragmatism, diligence, pioneering work, dedication to work, learning, struggle, and persistence all can be referred to as entrepreneurial spirit. It plays a role in motivating and restricting entrepreneurs. It is borrowed by entrepreneurs for accomplishing a self-improvement. Also, it features strong operability and must be realized in a commercial link. However, entrepreneurial spirit can be only practiced by entrepreneurs in the business activities of enterprises.

\subsection{Three Transcendences of the Entrepreneurial Spirit Development}

In 1776, the concept of "economic man" was first mentioned in economic works An Inquiry into the Nature and Causes of the Wealth of Nations by Adam Smith (founder of British classical political economics). In this book, entrepreneur's individual awareness is described clearly as the egoists who rationally pursue the maximization of self-interest. However, Adam Smith thinks sympathy is one of human being's instincts in his book the Theory of Moral Sentiments. The two seemingly contradictory theories are the best explanations to the struggles in the inner world of human beings. Therefore, how to balance the relationship between the two sides is a due quality of an excellent entrepreneur.

How is entrepreneurs transformed from "egoism" to "the spirit of utter devotion"? Three transcendences are necessarily undergone in general. The first transcendence - ego and capital and wealth is necessarily realized. The primary purpose of entrepreneurs is to meet the self-need and self-desire when wealth is primitively accumulated. However, entrepreneurs will deeply think whether the idle wealth is devoted to those people with a need when wealth accumulation is accomplished to a certain degree. Thus, the second transcendence-ego and moral consciousness emerges. This is a stage for entrepreneurs to improve from desire consciousness to an objective spirit 
and enter into the spirit of rationality and moral consciousness, while the self-development of entrepreneurs is to pursue higher spiritual freedom, but not to fulfill external spiritual needs. This freedom, after transcending physical consciousness and moral consciousness, is upgraded to a level of initiative humanistic spirit. As a result, the third transcendence-ego and humanistic spirit is achieved. Humanistic spirit refers to the spirit of individuals to think about the essence and significance of human beings' survival in terms of human beings as a whole and the universe after transcending the restrictions from the factors such as region, nationality, culture, and the times, so as to advocate the concern for human life, the maintenance of dignity, the pursuit of value, and the care about the fate .

\subsection{The Current Development of China's Entrepreneurs and the Social Responsibilities in Entrepreneurship}

\subsubsection{The Current Development of China's Entrepreneurs}

China's commerce and commercial civilization were originated in the middle of the 19th century. The first generation of China's entrepreneurs such as Xueyan HU and Lvtai LEI were all excellent masters in management. However, their images were fuzzy in the public. They were self-defined as "Shanxi merchants" or "Anhui merchants", so they were only thought to be businessmen in the society.

At the end of the 19th century and the beginning of the 20th century, a distinctive spirit was manifested by a new generation of entrepreneurs represented by Desheng RONG AND Jian ZHANG. They were not merely entrepreneurs, but were also self-defined as the mainstay of the society from the beginning of business establishment, because they were extensively involved in building roads, bridges, parks, education, urban planning, regional economic planning, and social security plan, in addition to the investment in industries. They endeavored to publicize the ideas of "save the nation by engaging in industry" and "save the nation by education" in all possible places. In 1922, an opinion poll was jointly organized by newspapers in Beijing, Shanghai, and other places, in which Jian ZHANG was elected as the most admired figure. The social recognition and respect to the generation of Jian ZHANG and Desheng RONG were unimaginable if they only focused the goal on the establishment of a successful business like their predecessors such as Xueyan HU and Lvtai LEI.

Modern Chinese entrepreneurs were the historic products of the economic reform and opening-up policy under the background of globalization, and therefore they were hundreds of years behind the development history of early western entrepreneurs. The characteristics of China's entrepreneurs can be concluded as follows:

First, the entrepreneurial team, based on proprietorship, can't meet the requirements of the modern economic development. According to statistics, $99 \%$ of the current enterprises in China are small and medium-sized, so the nature of China's entrepreneurial team is defined. Other types of entrepreneur groups, technocratic entrepreneurs, professional management entrepreneurs, and versatile entrepreneurs are mainly distributed in large state-owned enterprises, large Sino-foreign joint ventures, and a few large and medium-sized private enterprises.

Second, the rational consciousness of China's entrepreneurs is not enough. Modern rationality and scientific spirit are rarely seen in traditional Chinese culture, and also China is a closed country in politics before the implementation of the economic reform, so that the baptism by the modern rational spirit is not accepted by the entrepreneurs. Therefore, many irrational behaviors such as blindness and impulsivity appear in the field of entrepreneurial spirit from the beginning of opening-up and reform to now.

Third, entrepreneurial spirit is absent in the modern China's entrepreneurs. In the initial stage of the market economy, how to earn money and gain profit had been learned well by most entrepreneurs. However, the intension of entrepreneurial spirit is not enough understood and cognized by them. A portion of them still persist in the first transcendence (i.e. the stage of ego and capital and wealth), blindly seek after the increase of wealth quantities, and rest content with a lavish lifestyle, in which the utilization of resources is not maximized. The achievement of the second and third transcendences requires a period of time, but can't be made in a day.

\subsubsection{The Social Responsibilities in Entrepreneurship}

Entrepreneurs, who are compatible with a certain development level of social productive forces, are the groups reflecting the combination of responsibilities, rights, and interests in specific production relations, but also the representatives of the advanced social values. Entrepreneurs are both the beneficiaries of China's reform and opening-up policy and the creators of social wealth, and therefore entrepreneurs are required to shoulder the corresponding social responsibilities in the construction of a harmonious socialist society. The social responsibilities are mainly embodied in the following three aspects.

First of all, economic responsibility is basic to an entrepreneur. Entrepreneur, as a representative of corporate personality, should lead all employees to create products for customers, increase profits for the enterprises, and build 
wealth for the society.

Second, legal responsibility is mandatory an entrepreneur. Law is established or approved by the state, and should be implemented under the protection of the state's coercive force, so it is a social code of general binding forces to stipulate the rights and obligations of the parties. Under the restriction of the law, therefore, entrepreneurs are required to adjust all kinds of social production relationships related with them in the business activities and abide by the law in practice.

Finally and the most importantly, moral responsibility is necessarily assumed by entrepreneurs. The quantity of wealth should be proportional to the undertaken responsibilities. The consumption tendency marginal diminishing law is proposed by John Maynard Keynes (one of the most influential economists in the modern western economics), for proving the material consumption demand of human is limited. After the needs on material benefits are fulfilled, entrepreneurs come to realize the desires of other people in addition to their own. Their consciousness is transformed from centering at the society to other needs - that is, "I" is recognized to be subordinate to "we" or society. Thus, social consciousness becomes a main point of entrepreneurs "ego". The second transcendence (i.e. ego and moral consciousness) of entrepreneurial spirit is completed then. The accumulation of capital and wealth is seen by entrepreneurs as a process to fulfill the needs of their own, others, and society - that is, the spirit of self-regard is integrated with the spirit of altruism. An entrepreneur will definitely prove the value and significance of his existence again in a higher spiritual world if he thinks over needs not only in terms of his country and society but also from the mankind and the entire universe at a higher level of human consciousness. This is also a source to drive the inner positive enterprising spirit of many great entrepreneurs. Bill Gates once said that how to play the biggest role of the existing resources was a question to us. It is believed that the "human spirit" is the third transcendence of the entrepreneurship really accomplished.

China's entrepreneurs are still in germination and there is still a wider space for them to promote. Experience and theories can be drawn from the western entrepreneurs. China is a cultural superpower, in which self-study and self-examination are the main traditions of the Confucian culture, so entrepreneurs possess a strong ability in learning and absorbing. Meanwhile, the group of Chinese entrepreneurs features a profound tradition of humanistic spirit. For all these reasons, hopes can be seen from Chinese entrepreneurs.

\section{The Relationship between Entrepreneurship and Pension Business}

Due to the aging of the population has become increasingly serious in our country, combining with the endowment career are in the primary stage in our country, which caused serious imbalance between supply and demand of endowment career in our country, if only depend on the construction investment of the government, it could be difficult to meet the needs of the elderly, but this is a very urgent problem, which requires the elite in our society, innovation home and practitioner to undertake the social responsibility together. Entrepreneurs mainly develop old programs from the following three aspects.

\subsection{Pension Business of Entrepreneurship}

\subsubsection{The Source of Funds}

Today's entrepreneurs are the first rich people in Chinese society, now it is the time to repay society, they can use their resources to donate in various forms, lend or set up funds to support the development of the cause of the elderly, the investment is likely to be long-term, and earnings may be much smaller than other areas or even be free, but as the elites in the society ,they have the obligation to assume this responsibility.

\subsubsection{The Supply of Facilities and Technical Support}

In today's society. a lot of enterprise are dedicated to provide services for the elderly, as the vulnerable groups in society the elderly are vulnerable to decoy of some unscrupulous merchants and tend to buy some health care products which has not real efficacy, of course, this is rare. Those products which depend on older products as the main business products can be donated to a pension institution or offer discounts on their old buyers, in order to meet the needs of the elderly.

\subsubsection{The Innovation of Business Model}

Of course, the above two points can solve some emergencies, but take temporary solution can not make effect on permanent cure, if just blindly claiming entrepreneurs to donate, so it will dry up in one day, the government can not play a role. As mentioned on the definition of Entrepreneurs, innovation is the core of the entrepreneurial spirit, if the existing pension business have been unable to meet the needs of the elderly, then you should change its business 
model to create new value, it should be the most proficiency in the entrepreneurs, what we say that entrepreneurship can promote the development of pension business, not only refers to money, more important on their wisdom, only change the original management mode can we fundamentally solve the needs of old people.

\subsection{The Pension Business of Entrepreneurs}

\subsubsection{Provides the Opportunities of the Innovation, and Platform of Self-surpassing}

Seemingly, entrepreneurship is unilateral for pension business role, but in fact the entrepreneurship got a boost in casual. Endowment career as a just reclaimed land is full of opportunities and challenges.but it is because of these difficulties entrepreneurs play their role in these stages, also provide the chance for their second beyond - self and moral consciousness.

\subsubsection{Enhance Its Brand Value}

Nonprofit organization turned off many enterprises, but it seems that unpaid labor actually hind potential value behind, such as in providing pension service for the elderly and let service personnel wear clothing with the company Logo, or labeling some of the company product introduction on pension equipment, these free equipments may be much cheaper than TV ads, and more direct than the phone sales. Herbal tea brand plus the stupa called wang lao ji (2008) donated 100 million yuan during the wen chuan earthquake and caused a sensation, wang laoji at that time not only won the brand promotion, also won the 120 billion profits in 2008, super camp 3 billion than in 2007.

"Send person rose, the hand have lingering fragrance", anything is interaction, pension business and entrepreneurship are also not exceptional, if in an extreme view of the spirit of entrepreneur in the third time, what they are doing will bring benefits to our grandchildren ease the burden of young people and creat more jobs for them.

\section{Presumption of Entrepreneurs on How to Promote the Development of Pension Business}

The main research object of entrepreneurship is according to whether the organization is a non-profit social organization, the research object of social entrepreneurship can be divided into the following three organization types:

\subsection{Nonprofit Folk Organization}

Referring not to make profit as the ultimate purpose, but create specific social value for certain people as the mission of the organization. Non-profit organization can produce certain economic surplus in operation process, but this surplus is used to ensure the realization of a specific social mission, not for the realization of personal wealth. This kind of organization is dedicated to provide compulsory pension services for those low-income elderly, especially those who have no right to enjoy the local government pension insurance, mainly refers to home care services, such as access to care, access to a bath care, access to care, access to rehabilitation training, home rehabilitation management guidance, maintenance center care, rehabilitation training in maintenance center care, short-term life care, short term health care, make care for people with dementia make life care in specific facilities, provides the lease or buy the cost of welfare appliances, residential renovation and home care assistance, etc. On one hand ,the source of funds depend on donations by entrepreneurs from the society, on the other hand, are provided funds by the for-profit enterprise, in order to maintain its basic operating costs, including the basic living facilities of pension institutions and nursing cost of related service personnel, can make basic guarantee to the needs of old people. Such groups generally should be controlled at about $20 \%$, too high can't stay in business, too low can't meet the demand.

\subsection{Mixed Organization Cooperate with Government}

This kind of organization is created jointly by the government and entrepreneurs, preferential policies and some of the money are provided by the government, and management and operation are provided by entrepreneurs. The suitable group is mainly the elderly who has the low income, they can afford to part of the endowment service fee, but the government and the enterprise will provide appropriate subsidies, make endowment fee in the range of affordable, the enterprise should control the balance of payments on the cost, make it operate with high efficient and innovate business model actively, some of the funds are surplus of for-profit enterprise. The advantage of mixed group is providing organic combination to the advantages of the government and entrepreneurs, and government clear policy barriers, supervise the operation, the entrepreneur is expert on innovation and efficiency, is able to make better use of resources, which can effectively reduce the waste of resources. This kind of organization should be the main force of endowment enterprise now, accounting for more than half would be more appropriate. 


\subsection{The For-profit Companies Whose Product or Service Has Social Value}

The characteristics of this kind of organization is creating profits and creating social value at the same time, well meet the social needs of specific people. Such enterprises mainly aim at the elderly who have enough economic source, at the same time of ensuring their basic life, providing some high-end equipment instruments to the old, such as intelligent toilet, automatic wheelchair, etc. The purpose of providing some high-end products is not to say providing different services, but use the benefit of these products to offset the shortfall of the front two, also meet the service requirements of different people. Such companies account for about $20 \%$. As shown in figure 1, it illustrates mutual relations of three different endowment enterprise management mode.

$\begin{aligned} & \text { Social donation } \\ & \text { profitable corporate profits }\end{aligned}$
$\begin{aligned} & \text { Governmental subsidies \& } \\ & \text { profitable corporate profits } \\ & \text { \&payment from the elderly }\end{aligned}$
Fayment from the elderly
Financial Sources
organizations

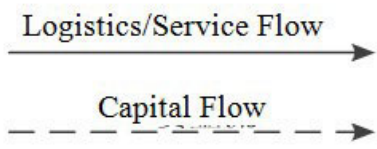

Figure 1. The mutual relationship among three endowment service management models

All sorts of groups will be covered if the three seemingly unrelated organizations are united together. These organizations are linked by a capital chain. In this way, demands exceeding supplies and a waste of resources will not be caused, and ultimately endowment undertakings will be developed harmoniously in China.

\section{The Breed of Entrepreneurial Spirit}

The cultivation of entrepreneurship is a complicated system engineering, the cultivation of entrepreneurial spirit mainly comes from two aspects, one is to create a good atmosphere suitable for the foster of entrepreneurial spirit in external, the second is emphasizing the shape of his character for the entrepreneur.

\subsection{Foster Entrepreneurship from the Reform of Higher Education}

The courses of entrepreneurial spirit should be widely set up in the university, cultivate their innovation consciousness, exercise their skills. Because the university should be the innovation place. Drucker pointed out that the emergence and development of entrepreneurship is the emergence and development of American university, the university can be stimulated to independence and innovation by entrepreneurship and eliminate psychology and behavior relies heavily on state and government, strive for and protect university autonomy and independence, graduates will no longer be just job seekers, and will be the creator of jobs

\subsection{Improve the Environment of Cultivating the Spirit of the Entrepreneur from the Government Functions}

Under the condition of modern market economy, we should improve the socialist market economic system and establish a just, fair and open market environment, protect the legitimate rights and interests of enterprises and entrepreneurs. Improve the entrepreneur's constraints and incentive mechanism, improve the whole quality of the entrepreneurs, fulfill the government's social management and public service function, lay emphasis on respect and protection of enterprise innovation behavior at the same time, the government should also pay attention to reduce 
barriers to entrepreneurship, reduce the cost of people who enter the threshold of entrepreneurs, which firstly make citizens entrepreneurship becomes relatively easy, the cultivation of entrepreneurial spirit is of far-reaching significance.

\subsection{From the Establishment of the Legal System to Regulate the Entrepreneurial Spirit}

Continuity and robustness of the economic system and economic policy, is the basis of micro behavior subject enterprises and entrepreneurs decision-making behavior. In a constantly changing social and economic system, enterprise and the entrepreneur will feel insecure and uncertain. Operators should establish a market allocation mechanism, the selection of entrepreneurs should adapt to the market adjustment, the formation of the market mechanism, which not only speed up the establishment and improvement of the professional manager team, but also overcome the institutional harriers of the growth of the entrepreneur, which is conducive to the breed of entrepreneurship.

\section{Summary}

Entrepreneurs are the beneficiaries of China's reform and opening up, is one of the first rich group of reform and opening up, is especially the founders of the social wealth, they have a bounden responsibility for the construction of socialist harmonious society. On one hand, the social harmony needs all citizens to build together, as ordinary citizens, as a special group with both economic strength and social activity, how can we live up to its responsibility? Especially when faced with the problem of aging society, entrepreneurs should be duty-bound, stand up, make due contribution for our parents, for ourselves and for our children, also perform its mission in the name of the entrepreneurial.

\section{References}

Adam Smith. (1972). The nature of the national wealth and causes research. Beijing: the commercial press.

Li Bing-xin. (2011). The functions of China's non-governmental organizations in the social security system. Journal of Liaoning Administration College, 2011(4).

Meng Hua-xing, \& Ji Xiao-jiang. (2012). Development of entrepreneurial spirit and the innovation and methods of the enterprise. Beijing: China economic publishing house.

Tian Yu-rong. (2008). Governmental organizations and community development. Learning and Exploration, 2008(7), 45-50.

Wang Yan-qiao. (2004). Thinking about entrepreneurship. Zhejiang academy of social sciences, 2004(5).

Zhao Jian-mei, \& Dai Rui. (2009). Several problems analysis about the corporate social responsibility. Modern management science, 2009(11).

Zheng Bing-wen. (2011). China's pension fund development report. Beijing: Economic management publishing house.

Zheng Yong-lan, \& Lu Liu-qing. (2010). The study on the non-governmental organization in social security: Features, Problems and Countermeasures. Journal of Nanjing Institute of Technology, 2010(2). 